\title{
Synthesis of patterned enzyme-metal- organic framework composites by ink-jet printing
}

\author{
Miao Hou ${ }^{1}$, Haotian Zhao ${ }^{2}$, Yi Feng ${ }^{1}$ and Jun Ge ${ }^{1 *}$ (I)
}

\begin{abstract}
Objectives: This report explores the possibility of synthesizing enzyme-metal-organic framework (MOF) composites by ink-jet printing.

Results: This study demonstrates that the direct synthesis of patterned enzyme-metal-organic framework (MOF) composites on various substrates including paper and polymeric films can be readily achieved by ink-jet printing bio-inks containing protein molecules, metal ions, and organic ligands loaded, respectively, in different cartridges. The formed Cytochrome c (Cyt c)-MOF composites on filter paper by ink-jet printing can be used for rapid detection of hydrogen peroxide in solution.

Conclusions: This technique opens possibilities of scalable, controllable, and designable fabrication of functional protein-MOF hybrid surface with promising applications in future bio-related application fields such as biosensing, wearable bioelectronics, artificial biomimetic membranes, and tissue engineering.
\end{abstract}

Keywords: Immobilized enzyme, Metal-organic frameworks, Ink-jet printing

\section{Background}

As a type of designable porous materials with numerous structural possibilities, metal-organic frameworks (MOFs) have been witnessed with their great progress in recent years. The focus of MOF applications is gas storage, separation, sensing, and catalysis (Furukawa et al. 2013; Hayashi et al. 2007; Sumida et al. 2011; Zhou et al. 2012). Moreover, MOFs also have shown great potentials in hosting biomolecules such as enzyme (or protein), explored by pioneering work from several groups in recent years (Lykourinou et al. 2011; Chen et al. 2012; Deng et al. 2012; Lyu et al. 2014; Shieh et al. 2015; Liang et al. 2015a; Feng et al. 2015; Li et al. 2016a, b, c; Lian et al. 2016, 2017; Liao et al. 2017; Zhang et al. 2017; Wu et al. 2015a, b; Hou and Ge 2017). The rigid but porous structure of MOFs makes them ideal for immobilizing

\footnotetext{
*Correspondence: junge@mail.tsinghua.edu.cn

${ }^{1}$ Key Lab for Industrial Biocatalysis, Ministry of Education, Department of Chemical Engineering, Tsinghua University, Beijing 100084, China Full list of author information is available at the end of the article
}

flexible protein molecules to increase the overall structural stability of protein. Benefited from the protection effect of MOF scaffolds, the incorporated enzyme can resist to various harsh environments that are harmful to fragile native enzyme, (Shieh et al. 2015; Liang et al. 2015a; Feng et al. 2015) even at protein-denaturing conditions (Liao et al. 2017; Wu et al. 2017). The enhanced stability makes enzyme-MOF composites promising for industrial and biomedical applications such as biocatalysis at harsh conditions (Lykourinou et al. 2011; Feng et al. 2015; He et al. 2016), enzymatic degradation of nerve agents, (Li et al. 2016a, b) stabilizing tobacco mosaic virus (Lian et al. 2016), and increasing sensitivity of biosensors (Lyu et al. 2014; Zhang et al. 2017). In addition, the tailor-made pore structures of MOFs realized the fitting of multiple enzymes in position for highly efficient enzyme cascade (Wu et al. 2015a, b; Lian et al. 2016).

As exemplified by the above studies, two strategies of synthesizing enzyme-MOF composites have been developed. One is the post-immobilization strategy. For example, by incubating enzyme (or protein) molecules with 
pre-synthesized MOFs in aqueous solution, enzyme (or protein) molecules were adsorbed into the large pores of MOFs (Lykourinou et al. 2011; Chen et al. 2012; Deng et al. 2012; Feng et al. 2015; Li et al. 2016a, b; Zhang et al. 2017; Lian et al. 2016). By chemical reactions between amino acids of enzyme and functional groups of pre-synthesized MOFs, enzyme molecules were attached on the surface of MOFs (Jung et al. 2011; Shih et al. 2012). Alternatively, another strategy is in situ one-pot synthesis of enzyme-MOF composites directly from enzyme, metal ions, and organic ligands in solution, which has been investigated by several groups (Lyu et al. 2014; Shieh et al. 2015; Liang et al. 2015a; Lian et al. 2016; Liao et al. 2017). All the above methods majorly rely on solutionbased procedures. However, the utilization of enzymeMOF composites in biosensors, bioelectronic devices, and other biomedical applications usually requires the patterned localization of biological components on special surface of devices. And it is challenging to precisely assemble or deposit the as-prepared enzyme-MOF composites with sizes ranging from nanometers to micrometers on substrate surface. Therefore, a scalable and controllable technique of readily positioning enzymeMOF composites on substrate surface with designable patterns would immediately advance the fabrication and practical application of enzyme-MOF composites in biosensors, wearable bioelectronic devices, artificial biomimetic membranes, and tissue engineering.

Stimulated by the in situ solution synthesis of enzymeMOF composites developed previously (Lyu et al. 2014; Wu et al. 2015a, b; Liang et al. 2015a), in this study, for the first time, we use a commercially available color inkjet printer to directly print enzyme-MOF composites on the surface of different substrates including filter paper, polyvinylchloride (PVC) film, poly(ethylene terephthalate) (PET) film, and hydrophilic printing film. Ink solutions containing zinc ions $\left(\mathrm{Zn}^{2+}\right)$, 2-methylimidazole (2-MeIM), and enzyme molecules were loaded in different cartridges, respectively $(C, M, Y$ cartridges as shown in procedure (1) of Fig. 1). Droplets of ink solutions were sprayed on the surface of printing substrates, allowing the mixing of precursors and in situ growing of enzymeMOF composites in the merged droplets on the surface before complete evaporation or infiltration of droplets. The mixing ratio of precursors and patterning of printed composites on substrates can be precisely designed by a computer controlling the printer. This synthesis technique using a commercially available color ink-jet printer (with price around 200 US dollars) allowed a facile and low-cost method to fabricate patterned enzyme-MOF composites on different substrates with dozens to hundreds of copies within minutes.

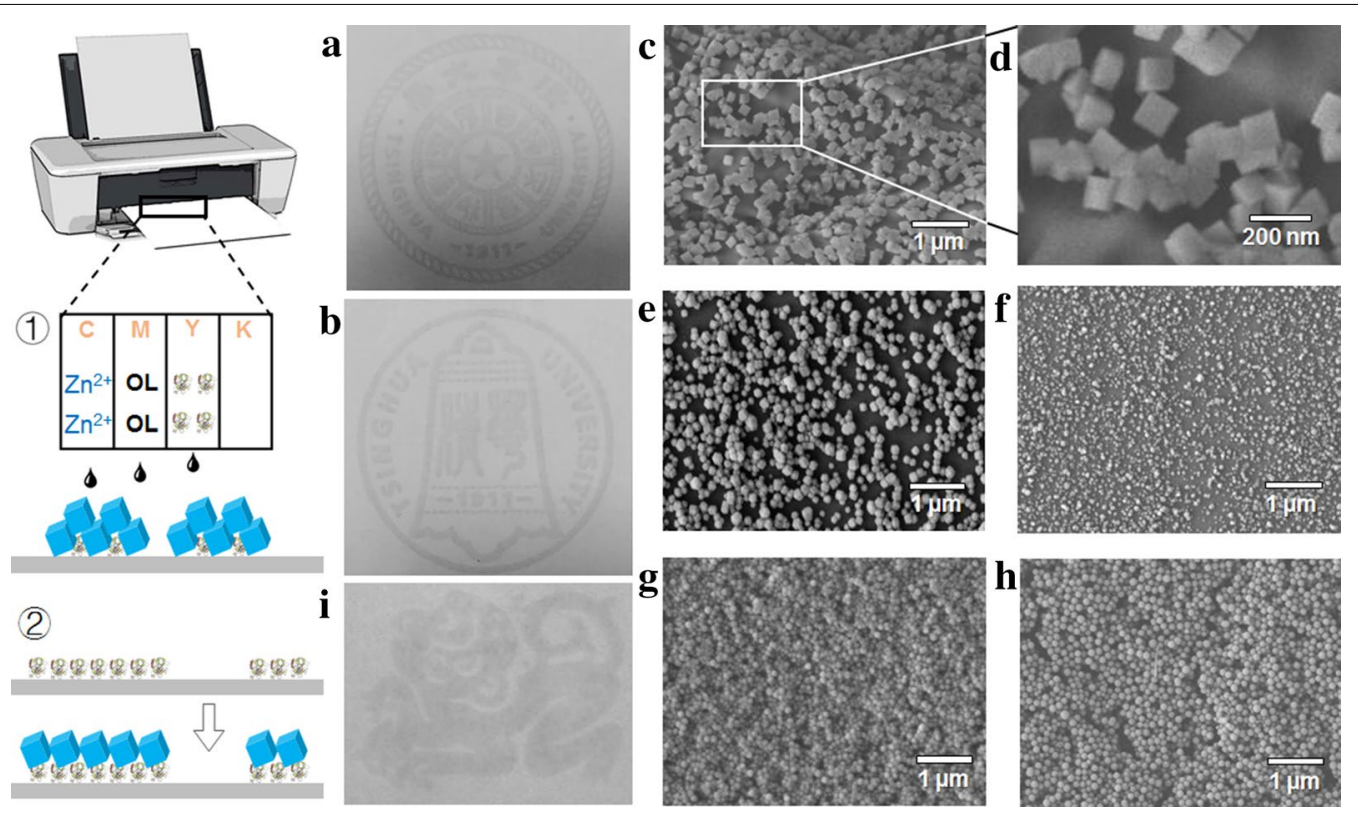

Fig. 1 a, b Printed patterns formed by ZIF-8 crystals on filter paper, and patterns (approximately $5 \mathrm{~cm} \times 5 \mathrm{~cm}$ ) are badges of Tsinghua University. SEM images of pure ZIF-8 particles printed on (c, d) filter paper ( 8 times printing), e PVC film (8 times printing), $\mathbf{f}$ PET film (8 times printing), $\mathbf{g}$ hydrophilic printing film (1 time printing). h SEM image of ZIF-8 particles grown on PET film printed with protein and a pattern (i) (approximately $5 \mathrm{~cm} \times 3 \mathrm{~cm}$ ) of a monkey representing lunar year of 2016 formed by ZIF-8 particles grown on PET film printed with protein. Organic ligand 2-MeIM is abbreviated as $\mathrm{OL}$ in the figure 


\section{Experimental section Materials}

Bovine serum albumin (BSA), 2-methylimidazole, 2,2'-azino-bis(3-ethylbenzothiazoline-6-sulfonic acid) diammonium salt (ABTS), dimethyl sulphoxide (DMSO), ethanol, ethylene glycol, tertiary butanol, Triton $\mathrm{X}-100$, fluorescein isothiocyanate (FITC), and rhodamine B were purchased from Sigma-Aldrich. Zinc nitrate hexahydrate, zinc acetate, hydrogen peroxide $\left(\mathrm{H}_{2} \mathrm{O}_{2}\right)$ were purchased from Alfa Aesar. Cytochrome c (Cyt c) from equine heart and horseradish peroxidase were purchased from Hoffmann-La Roche. Other chemicals are of analytical grade.

Printing procedure was carried out on a piezoelectric ink-jet printer Epson ME-10. The four ink cartridges were filled with self-formulated enzyme or precursors solutions; the graphics files to be printed were prepared by Adobes Photoshops CC software in CMYK color space. Whatman No. 1 filter paper was purchased from SigmaAldrich. Polyvinylchloride (PVC) film and poly(ethylene terephthalate) (PET) film were produced by Empero Co., LTD. and hydrophilic printing film was produced by FULEJET Co., LTD.

\section{Preparation of ink solutions}

Four different formulations of inks (Additional file 1: Table S1) were prepared to obtain an appropriate surface tension and viscosity in the range of $30-50 \mathrm{mN} / \mathrm{m}$ and $2-5 \mathrm{mPa}$, which is required for a smooth and continuous ink-jet printing. The viscosity measurement was carried out on a Physica MCR 301 rheometer under a shearing rate at $100 / \mathrm{s}$ at $25^{\circ} \mathrm{C}$. Inks $1-3$ were used to dissolve and print precursors of ZIF- 8 at required concentrations, and Ink 4 was used to dissolve and print protein and other molecules at required concentrations.

The inks were prepared before printing and filtered through a $0.45-\mu \mathrm{m}$ membrane prior to filling in the color cartridges. After each printing experiment, an automatic washing produce of the printer was conducted to avoid the block of nozzle by aggregates of metal ions, protein molecules, or other molecules.

For the investigation of formulation of inks, Inks 1-3 were used to dissolve zinc nitrate hexahydrate $\left(\mathrm{Zn}^{2+}\right)$ and 2-methylimidazole (2-MeIM) at a concentration of $125 \mathrm{mmol} / \mathrm{L}$ and $1 \mathrm{~mol} / \mathrm{L}$, respectively. The ink solution containing $\mathrm{Zn}^{2+}$ was loaded in the $\mathrm{C}$ cartridge and the ink solution containing 2-MeIM was loaded in the $M$ cartridge. The graphics files to be printed were prepared by Adobes Photoshops CC software in CMYK color space by fixing $C=100 \%$ and $M=100 \%$. The patterns to be printed were $3 \mathrm{~cm} \times 3 \mathrm{~cm}$ squares. The printing substrate was filter paper.

\section{Investigation of different printing substrates and printing} times

For the investigation of printing of pure ZIF-8 on different substrates including filter paper, PVC film, PET film, and hydrophilic film, Ink 1 was used to dissolve zinc nitrate hexahydrate $\left(\mathrm{Zn}^{2+}\right)$ and 2-methylimidazole (2-MeIM) at a concentration of $125 \mathrm{mmol} / \mathrm{L}$ and $1 \mathrm{~mol} / \mathrm{L}$, respectively. The ink solution containing $\mathrm{Zn}^{2+}$ was loaded in the $C$ cartridge and the ink solution containing 2-MeIM was loaded in the $M$ cartridge. The graphics files to be printed were prepared by Adobes Photoshops CC software in CMYK color space by fixing $C=100 \%$ and $M=100 \%$. The patterns to be printed were $3 \mathrm{~cm} \times 3 \mathrm{~cm}^{2}$. Various times of printing (interval time between each printing was $5 \mathrm{~min}$ ) were achieved by repeating the printing on the same pattern.

\section{Investigation of precursors concentrations and printing ratios}

For the investigation of concentrations of $\mathrm{Zn}^{2+}$ and 2-MeIM, Ink 1 was used to dissolve zinc nitrate hexahydrate $\left(\mathrm{Zn}^{2+}\right)$ and 2-methylimidazole (2-MeIM) at a concentration of $125 \mathrm{mmol} / \mathrm{L}$ (or $62.5 \mathrm{mmol} / \mathrm{L}$ ) and $1 \mathrm{~mol} / \mathrm{L}$ (or $0.5 \mathrm{~mol} / \mathrm{L}$ ), respectively. The ink solution containing $\mathrm{Zn}^{2+}$ was loaded in the $\mathrm{C}$ cartridge and the ink solution containing 2-MeIM was loaded in the $M$ cartridge. The graphics files to be printed were prepared by Adobes Photoshops CC software in CMYK color space by fixing $C=100 \%$ and $M=100 \%\left(\mathrm{Zn}^{2+} / 2-\right.$ MeIM molar ratio $\left.1: 8\right)$, or fixing $C=100 \%$ and $M=50 \%\left(\mathrm{Zn}^{2+} / 2\right.$-MeIM molar ratio 1:4). The patterns to be printed were $3 \mathrm{~cm} \times 3 \mathrm{~cm}$ squares. The printing substrate was filter paper.

\section{Printed protein-induced formation of ZIF-8}

Ink 4 was used to dissolve BSA at a concentration of $50 \mathrm{mg} / \mathrm{mL}$. Then the protein ink was loaded in Y cartridge and printed on PET film with a predesigned pattern. After drying the film with printed protein pattern at room temperature for $4 \mathrm{~h}$, the film was immersed in a solution containing $20 \mathrm{mmol} / \mathrm{L}$ of zinc acetate and $80 \mathrm{mmol} / \mathrm{L}$ 2-methylimidazole solution allowing reaction for $8 \mathrm{~h}$. After washing with DI water to remove unreacted metal ions and organic ligands, the film was dried at room temperature for $2 \mathrm{~h}$. The graphics files to be printed were prepared by Adobes Photoshops CC software in CMYK color space by fixing $Y=100 \%$.

\section{Printing Cyt c-ZIF-8 composites}

Ink 1 was used to dissolve zinc nitrate hexahydrate $\left(\mathrm{Zn}^{2+}\right)$ and 2-methylimidazole (2-MeIM) at a concentration of $125 \mathrm{mmol} / \mathrm{L}$ and $1 \mathrm{~mol} / \mathrm{L}$, respectively. Ink 4 was used to dissolve Cyt c (or Cyt c-FITC) at a concentration of $4 \mathrm{mg} /$ $\mathrm{mL}$. Then inks containing $\mathrm{Zn}^{2+}, 2-\mathrm{MeIM}$, and protein 
were loaded in $C, M, Y$ cartridges and printed on hydrophilic film with a predesigned pattern. With this order of cartridges, protein molecules can induce the formation of ZIF-8. The graphics files to be printed were prepared by Adobes Photoshops CC software in CMYK color space by fixing $C=100 \%, M=100 \%$, and $Y=100 \%$.

Ink 4 was used to dissolve rhodamine $B$ at a concentration of $4 \mathrm{mg} / \mathrm{mL}$ and was loaded in $\mathrm{K}$ cartridge. The graphics files to be printed were prepared by Adobes Photoshops CC software in CMYK color space by fixing $C=100 \%, M=100 \%$, and $Y=100 \%$ and adjusting the percentage of $K$ from 0 to $100 \%$ (0, 20, 40, 60, 80, 100\%).

\section{Printing Cyt c-ZIF-8 composites on filter papers to construct testing strips}

Ink 1 was used to dissolve zinc nitrate hexahydrate $\left(\mathrm{Zn}^{2+}\right)$ and 2-methylimidazole (2-MeIM) at a concentration of $125 \mathrm{mmol} / \mathrm{L}$ and $1 \mathrm{~mol} / \mathrm{L}$, respectively. Ink 4 was used to dissolve Cyt $\mathrm{c}$ at a concentration of $4 \mathrm{mg} / \mathrm{mL}$. Then inks containing $\mathrm{Zn}^{2+}, 2-\mathrm{MeIM}$, and protein were loaded in $C, M, Y$ cartridges and printed on filter papers as round patterns with diameters of $6 \mathrm{~mm}$. The graphics files to be printed were prepared by Adobes Photoshops CC software in CMYK color space by fixing $C=100 \%$, $M=100 \%$, and $Y=100 \%$.

Each round piece was utilized as a testing strip. $10 \mu \mathrm{L}$ of ABTS $\left(2.8 \mathrm{mg} / \mathrm{mL}\right.$ in water) and $10 \mu \mathrm{L}$ of $\mathrm{H}_{2} \mathrm{O}_{2}$ solution with different concentrations were dropped on the round pieces. Once the round strips turned green after $2 \mathrm{~min}$, the color intensity (gray value) was analyzed using the Image J2x software.

\section{Results and discussion}

The synthesis of pure MOF crystals was first investigated by the ink-jet printing method, loading inks containing $\mathrm{Zn}^{2+}$ and 2-MeIM in $\mathrm{C}$ and $\mathrm{M}$ cartridges and printing the ink on substrate according to predesigned patterns. Patterns designed by computer can easily be generated by the in situ formed ZIF-8 particles on surface by the ink-jet printing. Figure $1 \mathrm{a}, \mathrm{b}$ shows the photos of printed badges of Tsinghua University produced by in situ formed ZIF-8 particles. Figure $1 \mathrm{c}-\mathrm{g}$ shows scanning electron microscope (SEM) images of printed MOF crystals on different substrates including filter paper, PVC film, PET film, and hydrophilic printing film. ZIF-8 crystals with regular shapes similar as that produced in solution (Lyu et al. 2014; He et al. 2016) were in situ formed on substrate surface, as exemplified in Fig. 1d. Surface powder X-ray diffraction (XRD) pattern (Additional file 1: Figure S1) suggests that the printed ZIF- 8 has the same crystalline structure as that synthesized in solution (Lyu et al. 2014; He et al. 2016). Systematic studies revealed that inks with an appropriate surface tension and viscosity in the range of $30-50 \mathrm{mN} / \mathrm{m}$ and $2-5 \mathrm{mPa} \mathrm{s}$ are ideal for continuous printing (Additional file 1: Table S1). A combination of dimethyl sulfoxide (DMSO), ethanol, and ethylene glycol (at a volume ratio of 4:9:6) was the best solvent among others to print precursors of ZIF-8, and an optimized $\mathrm{Zn}^{2+} / 2$-MeIM printing molar ratio of $1 / 8$ produced more ZIF-8 particles (Additional file 1: Figures S2, S3). In addition, each substrate can be repeatedly printed for several times to increase the productivity of ZIF-8 particles on substrate surface (Additional file 1: Figure S4). As shown in Fig. 1c-f, the average size of the crystals formed on filter paper, PVC, and PET was 100, 70, and $30 \mathrm{~nm}$, respectively. In addition, denser particles were formed on filter paper than on PVC and PET films. According to the mechanism of a color ink-jet printer, droplets of inks in different cartridges are separately sprayed on surface and droplets are merged together once deposited on surface. Therefore, it is possible that more hydrophilic surface (for example, filter paper made of cellulose fibers) can facilitate the merging of different droplets containing $\mathrm{Zn}^{2+}$ or 2-MeIM to generate more ZIF-8 particles with larger particle size. To further demonstrate this hypothesis, we printed ZIF-8 particles on hydrophilic printing film by only one time and a high density of ZIF- 8 particles was readily achieved (Fig. 1g). Here, with the above results, we can conclude that MOF crystals can be readily formed on the surface of substrate by ink-jet printing and a hydrophilic environment is helpful for the formation of MOF crystals.

Therefore, we wonder if the presence of protein molecules which are hydrophilic biomacromolecules would also advance the formation of MOF crystals on surface. Thus, to investigate the effect of protein, another inkjet printing process was utilized as shown in procedure (2) of Fig. 1. Protein molecules (bovine serum albumin, BSA) were first printed on PET film and created areas with more hydrophilic surface. Then, when immersing the protein-printed PET film in solution containing $\mathrm{Zn}^{2+}$ and 2-MeIM, dense ZIF-8 particles were in situ formed (Fig. 1h) on the protein layer. To prove that ZIF-8 particles were preferably formed on the protein layer, a pattern of a monkey was constructed by printing protein molecules on a hydrophilic film, followed by immersing the film in aqueous solution containing $\mathrm{Zn}^{2+}$ and 2-MeIM. After this treatment, a clear and vivid pattern of monkey (Fig. 1i) was created due to the in situ formation of ZIF-8. SEM image of the cross section revealed that the thickness of the MOF layer was about $20 \mu \mathrm{m}$ (Fig. 2a) and the MOF layer was observed consisting of many ZIF-8 nanoparticles with size around $100 \mathrm{~nm}$ at a higher resolution under SEM (Fig. 2b). After ink-jet printing protein as patterned spots with size around $200 \mu \mathrm{m}$ on hydrophilic film, the film was immersed in aqueous solution 

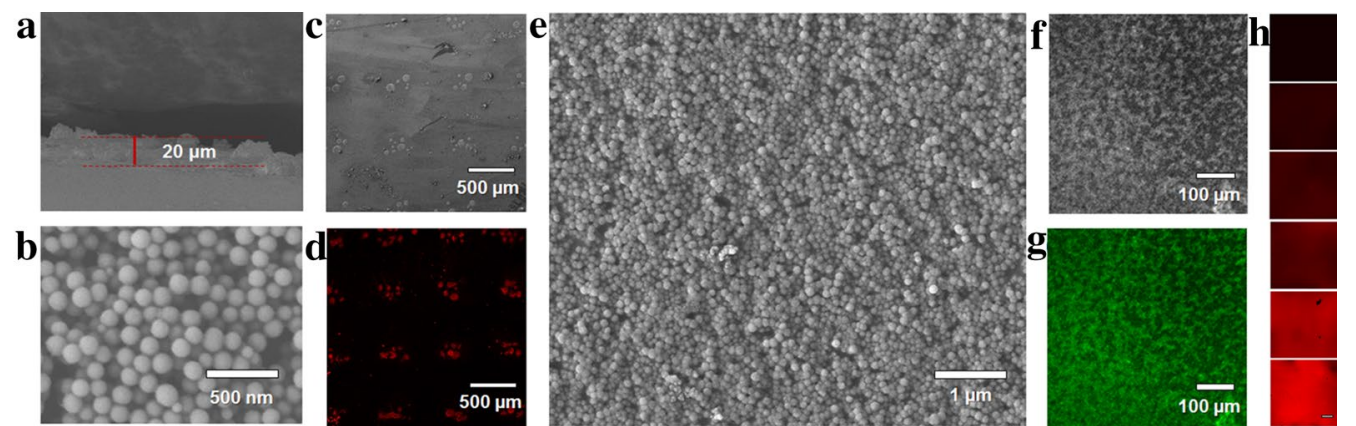

Fig. 2 SEM images of a ZIF-8 layer and $\mathbf{b}$ ZIF-8 nanoparticles formed on PET film printed with protein. $\mathbf{c}$, $\mathbf{d}$ SEM and fluorescent image of rhodamine B-incorporated ZIF-8 formed on PET film printed with protein spots. e SEM image of Cyt C-ZIF-8 composites on hydrophilic film by onetime printing. $\mathbf{f}, \mathbf{g}$ Bright-field image and fluorescent image of FITC-labeled Cyt c-ZIF-8 composites on hydrophilic film. $\mathbf{h}$ Fluorescent images of rhodamine B-incorporated Cyt C-ZIF-8 composites on hydrophilic film (up to down: 0, 20, 40,60, 80, 100\% K value, while C, $M, Y$ values are $100 \%$ as constant). Scale bar is 500 Âum long in (h)

containing $\mathrm{Zn}^{2+}$, 2-MeIM, and rhodamine $\mathrm{B}$. It is clearly observed that ZIF-8 was precisely formed on the region where protein was printed (Fig. 2c) and the fluorescent molecule rhodamine B was incorporated in ZIF-8. This precisely formation of MOFs on protein patterns proves that hydrophilic protein molecules can induce the formation of MOFs (Liang et al. 2015b). These results prove that the presence of protein molecules highly facilitates the synthesis of MOF.

Last, we carried out the process of printing enzyme and MOF precursors at the same time to form the enzymeMOF composites on surface directly. Ink solutions containing $4 \mathrm{mg} / \mathrm{mL}$ Cytochrome c (Cyt c), $125 \mathrm{mM} \mathrm{Zn}^{2+}$, and $1 \mathrm{M}$ 2-MeIM were loaded in different cartridges (C, $M, Y$ cartridges as shown in procedure (1) of Fig. 1) and were directly printed on the surface of hydrophilic film. SEM image in Fig. 2e shows that just one-time printing forms a high density of nanoparticles with size of $\sim 100 \mathrm{~nm}$, which are similar as the ZIF- 8 crystals prepared by the protein-induced synthesis (Fig. 1h, 2b). Surface powder X-ray diffraction (XRD) pattern (Additional file 1: Figure S1) suggests that the printed Cyt cZIF-8 composites have crystalline composition similar as pure ZIF-8; however, due to the small particle size and the presence of protein molecules, the XRD pattern shows widened peaks and the existence of amorphous composition. To prove the successful incorporation of protein in the composites, Cyt $\mathrm{c}$ was first labeled with fluorescein isothiocyanate (FITC) and subjected to the same printing process. The hydrophilic film printed with protein-ZIF-8 composites was then washed with DI water to remove the unreacted $\mathrm{Zn}^{2+}, 2-\mathrm{MeIM}$ and free Cyt c. By measuring the fluorescence intensity of Cyt c-FITC in the supernatant, the incorporation ratio of protein was calculated as $\sim 75 \%$. This result indicates that most of the protein is embedded in the ZIF- 8 particles instead of being absorbed on the surface of MOF layer. In another word, the protein molecules induce the formation of ZIF-8 particles around. To further calculate the weight percentage of protein in the Cyt c-ZIF-8 composites, small pieces of the printed hydrophilic film were immersed in acid solution to dissolve the composites, followed by the determination of Fe and $\mathrm{Zn}$ amounts through inductively coupled plasma mass spectrometry (ICP-MS) (Additional file 1: Table S2). As there is one equiv of Fe per protein, the weight percentage of Cyt $\mathrm{c}$ in composites was calculated to be around $15 \%$. The fluorescent image of the FITC-labeled Cyt c-ZIF-8 composites on hydrophilic film after washing (Fig. 2f, g) again proves the incorporation of protein with a dense and equal distribution.

From the above results, we conclude that the formation of enzyme-MOF composites on substrate surface with predesigned patterns can be easily achieved by a color ink-jet printing technique and the hydrophilic surface facilitates the formation of ZIF-8 particles possibly due to the enhanced merging process of microdroplets on hydrophilic surface. Moreover, the presence of protein in printing process further increases the hydrophilic nature of the microdroplets and the surface, thus further facilitates the formation of ZIF-8 particles with a high density on the hydrophilic surface by just one-time printing (Fig. 2e). Protein molecules, Cyt c, can be easily incorporated in ZIF-8 particles by this printing technique as they induce the formation of ZIF- 8 in merged microdroplets. In addition to protein incorporation, the color ink-jet printing technique is expandable to using more cartridges to incorporate other functional components in composites with a predesigned ratio at the same time (Zhang et al. 2014a, b). For example, rhodamine 
$\mathrm{B}$ was loaded in $\mathrm{K}$ cartridge and encapsulated in the Cyt c-ZIF-8 composites. As shown in Fig. 2h, with the preset printing ratio of $\mathrm{K}$ cartridge increased from 0 to $100 \%$, the red fluorescence was observed to be increased accordingly, suggesting a controllable encapsulation by this printing technique.

As an application of this printing technique in scalable and designable fabrication of biosensors with low cost, Cyt c-ZIF-8 composite was printed on filter paper as round patterns with diameters of $6 \mathrm{~mm}$. Each round piece was utilized as a testing strip for $\mathrm{H}_{2} \mathrm{O}_{2}$ in solution. The incorporated Cyt c can catalyze the oxidation of ABTS by $\mathrm{H}_{2} \mathrm{O}_{2}$, with forming a green colored product (Fig. $3 \mathrm{a}$ ) which can be determined by naked eyes or a color intensity analysis software. For a typical testing, $10 \mu \mathrm{L}$ of 2,2'-azino-bis-(3-ethylbenzthiazoline-6-sulfonic acid) (ABTS) $\left(2.8 \mathrm{mg} / \mathrm{mL}\right.$ in water) and $10 \mu \mathrm{L}$ of $\mathrm{H}_{2} \mathrm{O}_{2}$ solution with different concentrations were dropped on the round pieces. Once the testing strips turned green after $2 \mathrm{~min}$, the intensity of the color directly reflected the concentration of $\mathrm{H}_{2} \mathrm{O}_{2}$ in solution (Fig. 3b). In contrast, the same amount of native Cyt $\mathrm{c}$ printed on the same round piece without ZIF-8 cannot catalyze the reaction and produce any color change in the same detection time due to the low peroxidase activity of native Cyt c. The Cyt c incorporated in ZIF-8 shows enhanced activity compared to native Cyt $c$, reasons of which are majorly the activation effect of $\mathrm{Zn}^{2+}$, increased apparent affinity of Cyt c-ZIF-8 composite towards $\mathrm{H}_{2} \mathrm{O}_{2}$, and the more exposed active site of the incorporated Cyt $\mathrm{c}$ as investigated by several previous studies (Lyu et al. 2014; Zhang et al. 2017). The detection range of the testing strips is from 20 to
$120 \mathrm{mM}$, with a limit of $20 \mathrm{mM}$ by visible detection, making it promising for fast and convenient determination of $\mathrm{H}_{2} \mathrm{O}_{2}$ in solution. Detection of $\mathrm{H}_{2} \mathrm{O}_{2}$ is important in food, pharmaceutical, textile industries, and environmental protection (Zhang et al. 2014b; Jv et al. 2010). As an additive for microbial inhibiting or bleaching, $\mathrm{H}_{2} \mathrm{O}_{2}$ has been used in food industry (Nascimento et al. 2017). Due to the toxicity of residual $\mathrm{H}_{2} \mathrm{O}_{2}$, the presence of $\mathrm{H}_{2} \mathrm{O}_{2}$ is not allowed in food under European Union and Japanese regulations (Hsu et al. 2008). Food and Drug Administration (FDA) limits $\mathrm{H}_{2} \mathrm{O}_{2}$ to a very low concentration (Code of Federal Regulations 2017) in finished food packages. The low-cost testing strips produced by the scalable printing technique could be useful in analysis and regulation in food industry.

\section{Conclusions}

In summary, we explored a direct synthesis of enzymeMOF composites by ink-jet printing for the first time. By loading MOF precursors and protein in different cartridges of color printer and printing the inks according to predesigned patterns, protein-MOF composites can be easily in situ generated on the surface of various substrates such as paper and polymeric films due to the merging of microdroplets containing precursors and protein on surface. The results show that the printed MOF and protein-MOF composites can highly preserve the morphology and crystalline structure similar as pure MOF synthesized in solution. Hydrophilic surface and the presence of hydrophilic protein facilitates the formation of a high density of MOF on surface. As an example, the printed Cyt c-ZIF-8 composites on filter paper

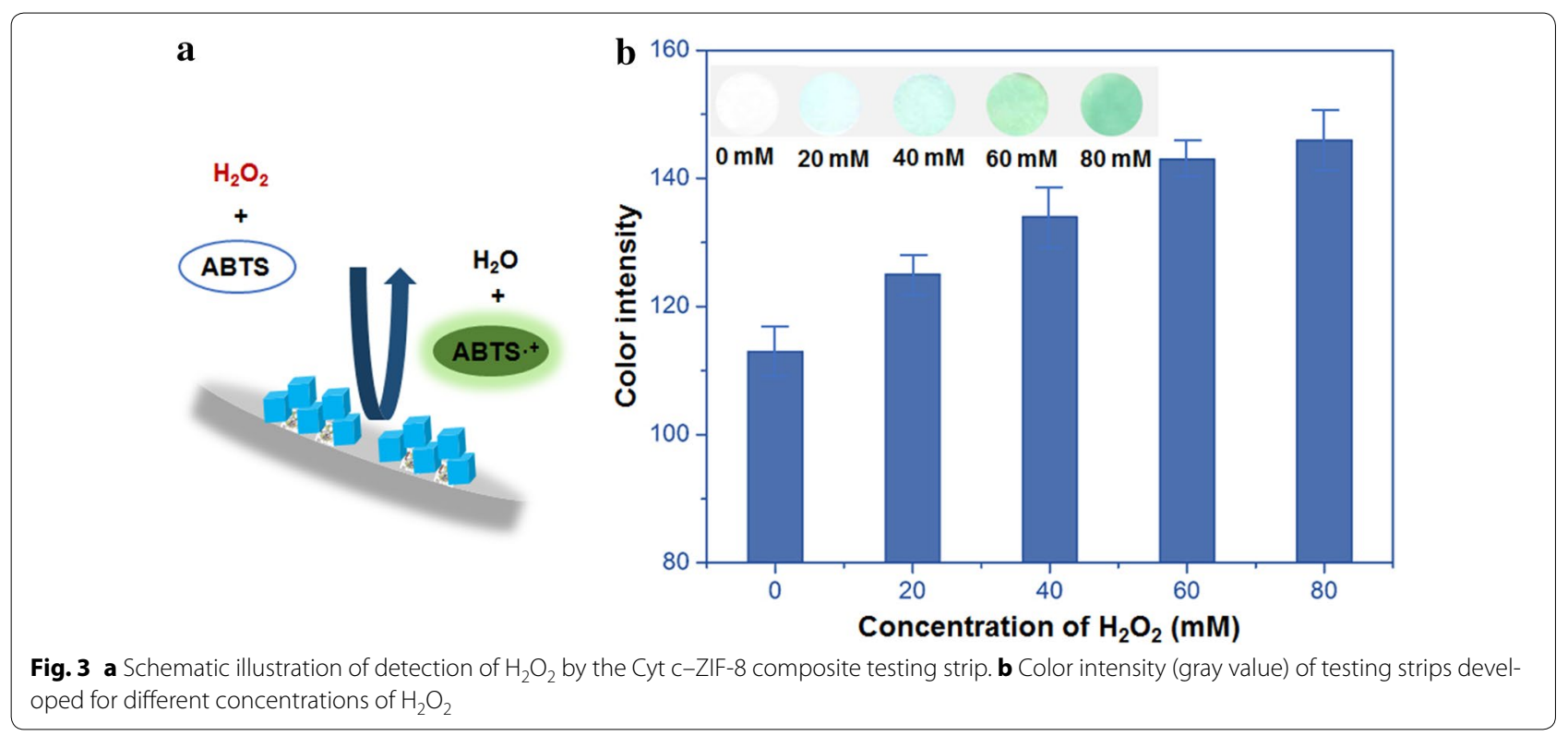


exhibits higher activity than native protein and can be used as low-cost testing strips for fast and facile $\mathrm{H}_{2} \mathrm{O}_{2}$ detection in food industry. This technique provides new possibilities of scalable, controllable, and designable fabrication of functional protein-MOF hybrid surface with many important applications in fields such as biosensing, wearable bioelectronics, artificial biomimetic membranes, and tissue engineering.

\section{Additional file}

Additional file 1. Supporting information for the detailed experimentals and characterization.

\section{Abbreviations}

MOF: metal-organic framework; Cyt c: Cytochrome c; ZIF-8: zeolitic imidazolate frameworks-8; SEM: scanning electron microscope; TEM: transmission electron microscope; XRD: X-ray diffraction; 2-MeIM: 2-methylimidazole; BSA: bovine serum albumin; ABTS: 2-methylimidazole, 2,2'-azino-bis(3-ethylbenzothiazoline-6-sulfonic acid) diammonium salt3; PVC: polyvinylchloride; PET: poly(ethylene terephthalate)

\section{Authors' contributions}

$\mathrm{MH}$ and $\mathrm{JG}$ designed the experiments. $\mathrm{MH}$ and $\mathrm{HZ}$ performed the experiments. $H Z, Y F, X W$, and JG drafted the manuscript. $M H, H Z$, and JG contributed to the discussion. All authors read and approved the final manuscript.

\section{Author details}

${ }^{1}$ Key Lab for Industrial Biocatalysis, Ministry of Education, Department of Chemical Engineering, Tsinghua University, Beijing 100084, China. ${ }^{2}$ Beijing National Day School, Beijing 100039, China.

\section{Acknowledgements}

Not applicable.

\section{Competing interests}

The authors declare that they have no competing interests.

\section{Availability of data and materials}

All data generated or analyzed during this study are included in this articles.

\section{Consent for publication}

Not applicable.

\section{Ethics approval and consent to participate}

Not applicable.

\section{Funding}

This work was supported by the National Key Research and Development Plan of China (2016YFA0204300), and the National Natural Science Foundation of China $(21622603,51573085)$.

\section{Publisher's Note}

Springer Nature remains neutral with regard to jurisdictional claims in published maps and institutional affiliations.

Received: 26 August 2017 Revised: 10 September 2017 Accepted: 15 September 2017

Published online: 23 September 2017

\section{References}

Chen Y, Lykourinou V, Vetromile C, Hoang T, Ming L, Larsen RW, Ma S

(2012) How can proteins enter the interior of a MOF? Investigation of Cytochrome c translocation into a MOF consisting of mesoporous cages with microporous windows. J Am Chem Soc 134:13188-13191. doi:10.1021/ja305144x

Code of Federal Regulations 21CFR178.1005 (2017). https://www.accessdata. fda.gov/scripts/cdrh/cfdocs/cfcfr/CFRSearch.cfm. Accessed 1 Apr 2017

Deng H, Grunder S, Cordova KE, Valente C, Furukawa H, Hmadeh M, Gándara F, Whalley AC, Liu Z, Asahina S, Kazumori H, O'Keeffe M, Terasaki O, Stoddart JF, Yaghi OM (2012) Large-pore apertures in a series of metal-organic frameworks. Science 336:1018-1023. doi:10.1126/science.1220131

Feng D, Liu T, Su J, Bosch M, Wei Z, Wan W, Yuan D, Chen Y, Wang X, Wang K (2015) Stable metal-organic frameworks containing single-molecule traps for enzyme encapsulation. Nat Commun 6:5979. doi:10.1038/ ncomms6979

Furukawa H, Cordova KE, O'Keeffe M, Yaghi OM (2013) The chemistry and applications of metal-organic frameworks. Science 341:1230444. doi:10.1126/science.1230444

Hayashi H, Cote AP, Furukawa H, O'Keeffe M, Yaghi OM (2007) Zeolite a imidazolate frameworks. Nat Mater 6:501-506. doi:10.1038/nmat1927

He H, Han H, Shi H, Tian Y, Sun F, Song Y, Li Q, Zhu G (2016) Construction of thermophilic lipase-embedded metal-organic frameworks via biomimetic mineralization: a biocatalyst for ester hydrolysis and kinetic resolution. ACS Appl Mater Interfaces 8:24517-24524. doi:10.1021/ acsami.6b05538

Hou M, Ge J (2017) Armoring enzymes by metal-organic frameworks by the coprecipitation method. Methods Enzymol 590:59-75. doi:10.1016/ bs.mie.2016.12.002

Hsu C, Chang K, Kuo J (2008) Determination of hydrogen peroxide residues in aseptically packaged beverages using an amperometric sensor based on a palladium electrode. Food Control 19:223-230. doi:10.1016/j. foodcont.2007.01.004

Jung S, Kim Y, Kim S, Kwon TH, Huh S, Park S (2011) Bio-functionalization of metal-organic frameworks by covalent protein conjugation. Chem Commun (Camb) 47:2904-2906 doi:10.1039/c0cc03288c

JV Y, Li B, Cao R (2010) Positively-charged gold nanoparticles as peroxidiase mimic and their application in hydrogen peroxide and glucose detection. Chem Commun 46:8017-8019. doi:10.1039/c0cc02698k

Li P, Moon SY, Guelta MA, Harvey SP, Hupp JT, Farha OK (2016a) Encapsulation of a nerve agent detoxifying enzyme by a mesoporous zirconium metalorganic framework engenders thermal and long-term stability. J Am Chem Soc 138(26):8052-8055. doi:10.1021/jacs.6b03673

Li P, Moon SY, Guelta MA, Lin L, Gómez-Gualdrón DA, Snurr RQ, Harvey SP, Hupp JT, Farha OK (2016b) Nanosizing a metal-organic framework enzyme carrier for accelerating nerve agent hydrolysis. ACS Nano 10(10):9174-9182. doi:10.1021/acsnano.6b04996

Li S, Dharmarwardana M, Welch RP, Ren Y, Thompson CM, Smaldone RA, Gassensmith JJ (2016c) Template-directed synthesis of porous and protective core-shell bionanoparticles. Angew Chem 128(36):10849-10854 doi:10.1002/ange.201604879

Lian X, Chen Y, Liu T, Zhou H (2016) Coupling two enzymes into a tandem nanoreactor utilizing a hierarchically structured MOF. Chem Sci 7:69696973. doi:10.1039/c6sc01438k

Lian X, Fang Y, Joseph E, Wang Q, Li J, Banerjee S, Lollar C, Wang X, Zhou H (2017) Enzyme-MOF (metal-organic framework) composites. Chem Soc Rev 46:3386-3401. doi:10.1039/c7cs00058h

Liang K, Carbonell C, Styles MJ, Ricco R, Cui J, Richardson JJ, Maspoch D, Caruso F, Falcaro P (2015a) Biomimetic replication of microscopic metalorganic framework patterns using printed protein patterns. Adv Mater 27:7293-7298. doi:10.1002/adma.201503167

Liang K, Ricco R, Doherty CM, Styles MJ, Bell S, Kirby N, Mudie S, Haylock D, Hill AJ, Doonan CJ (2015b) Biomimetic mineralization of metal-organic frameworks as protective coatings for biomacromolecules. Nat Commun. doi:10.1038/ncomms 8240

Liao FS, Lo WS, Hsu YS, Wu CC, Wang SC, Shieh FK, Morabito JV, Chou LY, Wu KCW, Tsung CK (2017) Shielding against unfolding by embedding enzymes in metal-organic frameworks via a de novo approach. J Am Chem Soc 139(19):6530-6533. doi:10.1021/jacs.7b01794

Lykourinou V, Chen Y, Wang XS, Meng L, Hoang T, Ming LJ, Musselman RL, Ma S (2011) Immobilization of MP-11 into a mesoporous metal-organic framework, MP-11@mesoMOF: a new platform for enzymatic catalysis. J Am Chem Soc 133:10382-10385. doi:10.1021/ja2038003 
Lyu F, Zahng Y, Zare RN, Ge J, Liu Z (2014) One-pot synthesis of proteinembedded metal-organic frameworks with enhanced biological activities. Nano Lett 14:5761-5765. doi:10.1021/nl5026419

Nascimento CF, Santos PM, Pereira-Filho ER, Rocha FR (2017) Recent advances on determination of milk adulterants. Food Chem 221:1232-1244. doi:10.1016/j.foodchem.2016.11.034

Shieh FK, Wang SC, Yen C, Wu C, Dutta S, Chou L, Morabito JV, Hu P, Hsu MH, Wu KCW (2015) Imparting functionality to biocatalysts via embedding enzymes into nanoporous materials by a de novo approach: size-selective sheltering of catalase in metal-organic framework microcrystals. J Am Chem Soc 137(13):4276-4279. doi:10.1021/ja513058h

Shih YH, Lo SH, Yang N, Singco B, Cheng Y, Wu C, Chang I, Huang H, Lin C (2012) Trypsin-immobilized metal-organic framework as a biocatalyst in proteomics analysis. ChemPlusChem 77:982-986. doi:10.1002/ cplu.201200186

Sumida K, Rogow DL, Mason JA, McDonald TM, Bloch ED, Herm ZR, Bae TH, Long JR (2011) Carbon dioxide capture in metal-organic frameworks. Chem Rev 112:724-781. doi:10.1021/cr2003272

Wu X, Ge J, Yang C, Hou M, Liu Z (2015a) Facile synthesis of multiple enzymecontaining metal-organic frameworks in a biomolecule-friendly environment. Chem Commun (Camb) 51:13408-13411. doi:10.1039/c5cc05136c
Wu X, Hou M, Ge J (2015b) Metal-organic frameworks and inorganic nanoflowers: a type of emerging inorganic crystal nanocarrier for enzyme immobilization. Catal Sci Technol 5:5077-5085. doi:10.1039/c5cy01181g

Wu X, Yang C, Ge J (2017) Green synthesis of enzyme/metal-organic framework composites with high stability in protein denaturing solvents. Bioresour Bioprocess 4:24. doi:10.1186/s40643-017-0154-8

Zhang Y, Bai X, Wang X, Shiu KK, Zhu Y, Jiang H (2014a) Highly sensitive graphene-Pt nanocomposites amperometric biosensor and its application in living cell $\mathrm{H}_{2} \mathrm{O}_{2}$ detection. Anal Chem 86:9459-9465. doi:10.1021/ ac5009699

Zhang Y, Lyu F, Ge J, Liu Z (2014b) Ink-jet printing an optimal multi-enzyme system. Chem Commun 50:12919-12922. doi:10.1039/c4cc06158f

Zhang C, Wang X, Hou M, Li X, Wu X, Ge J (2017) Immobilization on metalorganic framework engenders high sensitivity for enzymatic electrochemical detection. ACS Appl Mater Interfaces 9(16):13831-13836. doi:10.1021/acsami.7b02803

Zhou HC, Long JR, Yaghi OM (2012) Introduction to metal-organic frameworks Chem Rev 112:673-674. doi:10.1021/cr300014x

\section{Submit your manuscript to a SpringerOpen ${ }^{\circ}$ journal and benefit from:}

- Convenient online submission

- Rigorous peer review

- Open access: articles freely available online

- High visibility within the field

Retaining the copyright to your article

Submit your next manuscript at $\boldsymbol{\nabla}$ springeropen.com 